\title{
Waterproofing Technology for Underground-Fabricated Structure Joints Based on the Open Cut Method
}

\author{
Huang Mingli ${ }^{1}$, Yang $\mathrm{Ze}^{1}$, Tan Zhongsheng ${ }^{1}$, Wang Wenzheng ${ }^{2}$ \\ 1. School of Civil Engineering, Beijing Jiaotong University, Beijing 100044, China \\ 2. Beijing Municipal Construction Co., Ltd. Third Agency, Beijing 100176, China
}

\begin{abstract}
Compared with traditional cast-in-place structures, fabricated structures have the characteristics of saving energy, protecting the environment, eliminating mold, and short construction times. Fabricated structures have been developed rapidly in above-ground buildings. However, the use of underground-fabricated structures in China has only recently begun. Owing to the complexity of the underground environment, waterproofing underground-fabricated structure joints remains a problem. In this paper, based on an analysis of the joints of an underground-fabricated building and the current state of waterproofing technology, we propose the use of an epoxy grouting material, which is used to pot the prefabricated structure joint, and study the mechanical properties of the epoxy grouting material and its bonded concrete. Additionally, we introduce backfilling technology for prefabricated solidified soil in the foundation pit, and expound the effect of the prefabricated solidified soil on the waterproofing of the underground engineering structures. The research results provide good references for similar engineering projects.
\end{abstract}

Keywords: prefabricated structures; underground structure joint; epoxy grouting material; prefabricated solidified soil; waterproofing technology

\section{Introduction}

Accompanied by the acceleration of urbanization in China, urban land shortage, traffic congestion, and other issues have become increasingly prominent. The vigorous development and utilization of urban underground space is effective in solving the problems above. Further, with the rise of building industrialization, the application prospects of prefabricated structures have also become better; prefabricated components are the primary force components of prefabricated structures, in which the latter are assembled and connected to concrete structures. Compared with the traditional cast-in-place buildings, prefabricated buildings have many advantages: energy saving, environment protecting, and short construction period, and low cost. China's above ground-fabricated structure has achieved rapid development; however, the underground-fabricated structure has just started. The structural joint is a weak part of the prefabricated structure. The above ground-fabricated structure only needs to solve the problem of the connection strength at the joint of the structure. The underground-fabricated structure not only needs to solve the problem of connection strength at the joint, but also needs to ensure the waterproof aspect.

\section{Underground-fabricated structure of the joint form}

To solve the problem of waterproofing of the undergroundfabricated structure, it is necessary to understand the existing

Received date: November 18, 2017; Revised date: November 30, 2017

Corresponding author: Huang Mingli, School of Civil Engineering, Beijing Jiaotong University, Professor. Major research field is tunnel and underground engineering construction mechanics and environmental impact control technology. E-mail: huang_mingli@126.com

Funding program: CAE Advisory Project “Development Strategy for Urban Underground Space Planning in China” (2015-XZ-16)

Chinese version: Strategic Study of CAE 2017, 19 (6): 131-139

Cited item: Huang Mingli et al. Waterproofing Technology for Underground Fabricated Structure Joints Based on the Open Cut Method. Strategic Study of CAE, https://doi.org/10.15302/J-SSCAE-2017.06.019 
forms of the assembly structure. The underground-fabricated structure should use the mechanical connection, welding connection, tongue and groove connection, or socket connection [1].

Prestressed connection means providing tension to the wire or steel, and subsequently connecting them [2]. Prestressed connection nodes consume less energy and have less residual strain, damage, and strength loss. Prestressed connections no longer use the pouring of concrete at the construction site, but instead use a new type of directly assembled prestressed tendon components.

The mechanical connection is to connect the hole reserved in the joint part or the embedded nut with a bolt. The mechanical connection is convenient and quick. However, the common bolt connection also has many problems, e.g., the bolt is easy to loosen under a long-term dynamic load and the bolt aperture or the hole prone is easy to deviate; the presence of bolt holes will weaken the mechanical properties of the member cross-section, and the joint repair and replacement are inconvenienced. Prestressed connections and mechanical connections cannot guarantee the overall structural stability and waterproofing effect.

Welding refers to the use of mortar or concrete to create the protective layer and weld the joint parts of the steel or steel with anchor iron. High temperatures can render the steel material brittle and the residual stresses created during the welding process can cause brittle failures of the structure, all of which can affect the mechanical properties of the structure; however, welded connections also have advantages such as no wet-on-site operation, time conservation, and shortened construction period.

The tongue-and-groove connection can effectively improve the joint part capability to resist the bending moment. The deformation of the connection method is small, and the overall performance of the connection part is excellent (Fig. 1). In weld connections and tongue-and-groove connections, although the overall stability and waterproofing are guaranteed, the seams that are joined by both methods are infused with inorganic materials The inorganic materials are limited by temperature, not suitable for use in low temperature areas, and are low in adhesive strength [3].

Socket connections are suitable for construction site conditions that are poor or prone to uneven settlements. The flexible joint connection in socket connections is generally a combination of an elastic seal rubber ring and a water-swelled rubber ring (Fig. 2).

\section{Waterproofing of the underground-fabricated structure}

Prefabricated structures will produce a large number of assembly joints in the assembly process [4]. The existence of these joints not only affects the overall stability of the structure, but also poses a hazard to the waterproof performance of the structure. Failure to properly handle seams and failure to form a reliable waterproofing barrier at the seams may result in engineering accidents. Currently, the commonly used water-proof materials for cast-in-place concrete construction cannot meet the construction requirements for the seams of underground assembled structures.

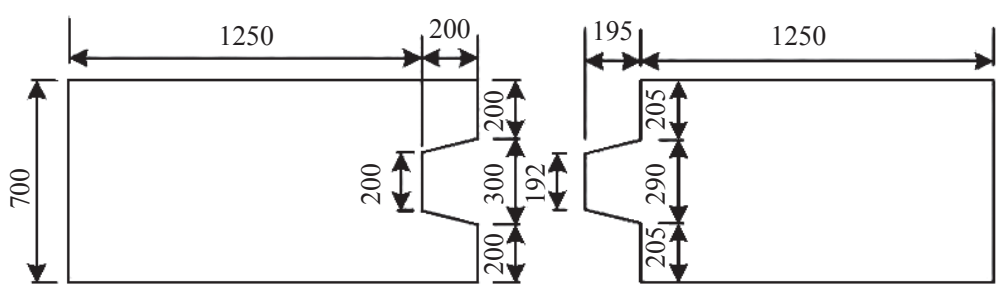

Fig.1. Tongue and groove joints (unit: $\mathrm{mm}$ ).

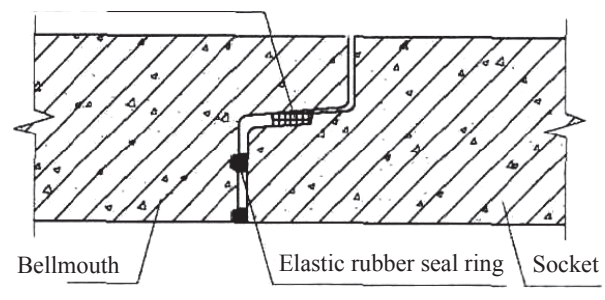

(a)

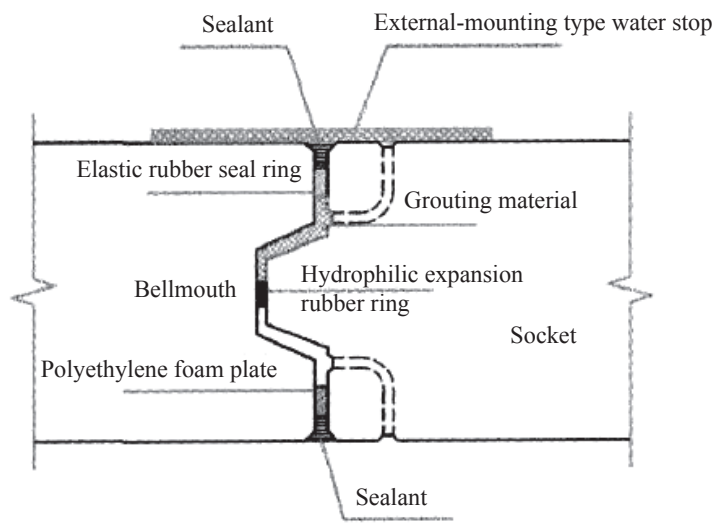

(b)

Fig. 2. Socket connections. 
Waterproofing techniques of prefabricated underground buildings have two kinds of structural systems: a prefabricated concrete box culvert and a laminated-slab concrete structure [5]. Prefabricated concrete box culverts are primarily used in underground integrated pipelines in urban areas. The waterproofing of the laminated-slab concrete structure system includes external waterproof structures, ordinary waterproof structures, and local reinforced waterproof structures.

\subsection{Prefabricated concrete box culvert}

A prefabricated concrete box culvert is a box-type structure, made of reinforced concrete, with fast construction; it is highly suitable for the construction of underground structures. A prefabricated concrete box culvert connection is primarily divided into the longitudinal locking device connection and the unrestricted locking device connection. Adjacent box culverts often use water-swellable rubber rings or sealed rubber rings for waterproofing (Fig. 3).

\subsection{Laminated-slab concrete structure system}

A laminated-slab concrete structural system consists of lami-

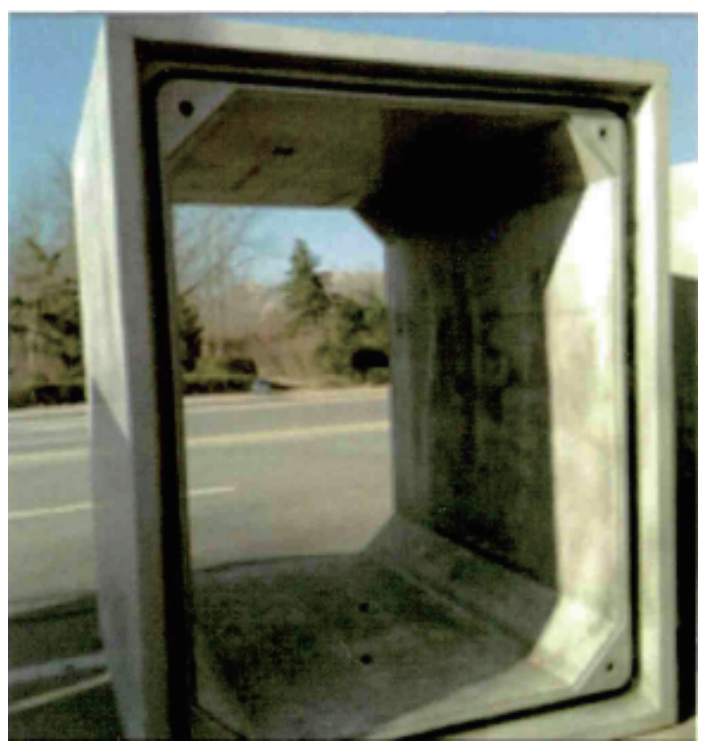

Fig. 3. Prefabricated concrete box culvert. nated wall panels, a laminated floor, and a cast-in-place concrete layer together. A laminated wall is a type of integrated wall, which is formed by the two inner and outer layers of prefabricated panels; the middle of the grid reinforcement is installed after the pouring of concrete between the two plates formed.

Fig. 4 shows the common waterproofing structure of the laminated wall seams. It is performed by placing a reinforcement cage at the seams and subsequently pouring the concrete once again. The waterproofing effect of this structure is excellent. The common waterproofing structure of the wall seams is suitable for nonpressurized water formation.

Fig. 5 shows the outer-wall waterproofing of the laminated wall seams. In this structure, waterproof mortar is applied to the seams of the laminated wall, followed by the waterproofing membrane. Because the prefabricated components have excellent waterproofing properties, they can form an enclosed space with the waterproofing membrane to form the first waterproofing layer. The internal prefabricated wallboard and the intermediate cast-in-place concrete layer can form a second waterproofing layer. The presence of dark columns at the seams improves the waterproofing of the subsurface structure as a whole. The structure can be used for underground engineering with underground confined water and good geological conditions.

Fig. 6 shows the local reinforced waterproofing of the laminated wall seams. The structure of the joints was designed to waterproof the weak parts in the prefabricated wall panels and to waterproof the mortar constitute the first waterproof layer. When the joints move, the waterproofed mortar will produce damages while leakage points are formed. Because of the horizontal and vertical water-stop strips fixed on the seams of cast-in-place concrete layers, the water stop and cast-in-place concrete form the second continuous waterproof layer. The structure is suitable when subsurface pressure water occurs and can easily produce the uneven settlement of the formation.

\section{Mechanical properties of epoxy grouting material}

Based on the analysis of the joint form and the status quo of waterproof technology in underground assembly buildings, this paper presents a method of potting the joint of prefabricated structure using an epoxy grouting material. Through the experimental study of the mechanical properties of the epoxy grouting

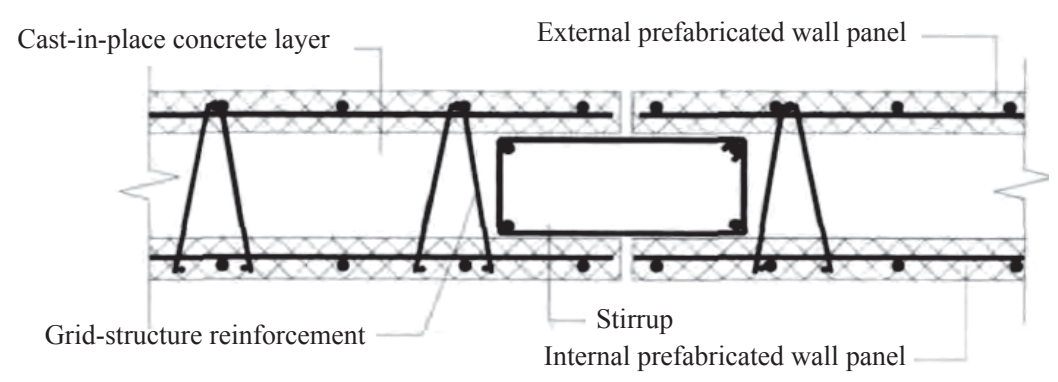

Fig. 4. General waterproof structure [5]. 


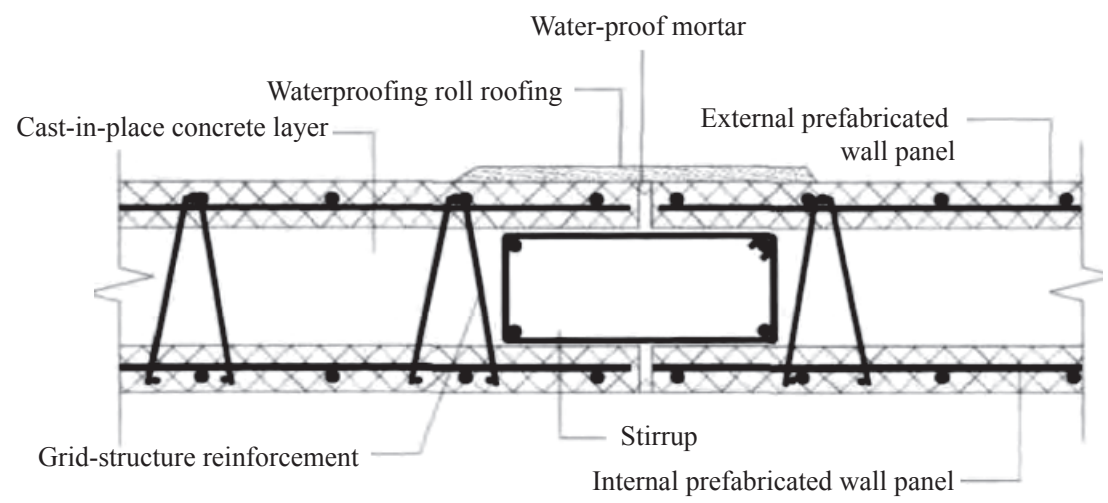

Fig. 5. External waterproof structure [5].

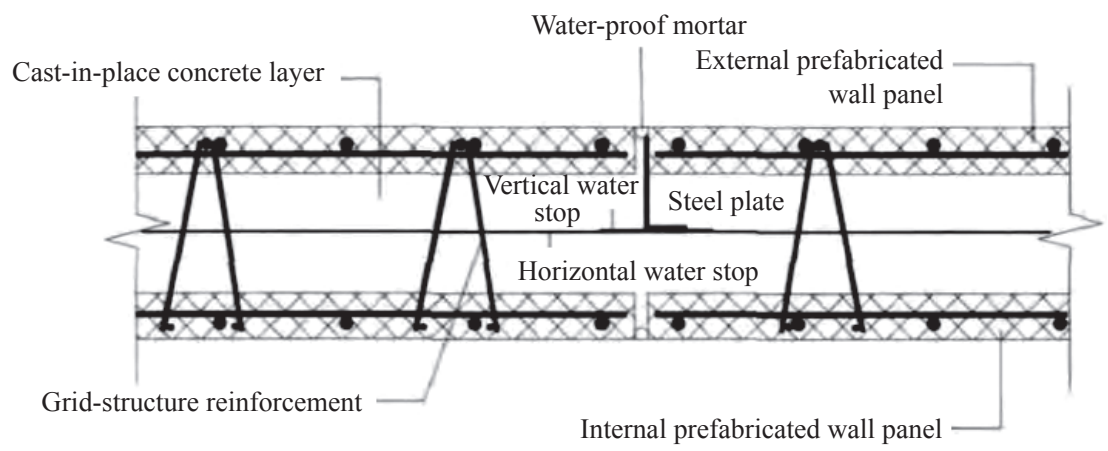

Fig. 6. Local enhanced waterproof structure [5].

material itself and its bonding concrete, we verified the suitability of epoxy grouts in prefabricated structures.

\subsection{Selection of grouting material research}

The epoxy grouting material is modified by a grouting material. The grouting material can be divided into two categories: nonchemical grout and chemical grout. Because the bonding strength of nonchemical grouts such as grout and clay slurry are lower, they are not suitable for this project; however, if modified cement-based materials are used, it is necessary to conduct preliminary tests to determine whether they are suitable for this project.

Cement-based materials are low cost, and can greatly reduce project costs. The primary disadvantages of the modified cement slurry are as follows: (1) the cement slurry tends to segregate easily, which tends to cause pipe clumping and clogging during the pouring process; (2) the shear strength of the cement grouting concrete is approximately $1 / 3$ of the shear strength of the concrete, and the bond shear strength is not sufficient; (3) the cement grout concrete tensile strength is much smaller than the tensile strength of concrete, and the bond tensile strength is insufficient. Therefore, the cement slurry is not suitable for use in this project.

The primary types and properties of the chemical grouting material are shown in Table 1. As shown, the uniaxial compressive strengths of waterglass, acrylamide, urea formaldehyde resin, lignin, and polyurethane grouting material may be less than
C50 (50 MPa); therefore, they should not be used in this project. Because of its specific gravity of approximately 0.94 , the viscosity of acrylic acid ester salt is only $2 / 3$ that of water. Precipitations are easily produced after adding aggregates. Therefore, it should not be added to the modified aggregate. It is not suitable for this project, and we presented the following to study and improve the epoxy resin slurry.

In this experiment, the epoxy resin base fluid uses the JGNG-type low-temperature perfusion building structural adhesive. As pure epoxy shrinks, the modulus of elasticity is compressed and incurs a high cost; therefore, we added quartz powder to modified epoxy resin slurry formulations, and physical, mechanical, and annotation tests were performed to determine the optimal formulation of the epoxy resin.

The physical and mechanical properties of the modified epoxy resin were determined by a large number of laboratory tests under different slurry ratios. The physical properties include density, viscosity, curing time, shrinkage, permeability, etc. The mechanical properties include compressive strength, elastic modulus, shear strength of concrete, concrete tensile bond strength, etc.

\subsection{Test introduction}

Through the design of bonding shear test and bonding tensile test, the mechanical properties of the epoxy grouting material 
Table 1. Primary types and performance list of chemical grouting material.

\begin{tabular}{|c|c|c|c|c|}
\hline Types & Primary classification & $\begin{array}{l}\text { Initial viscosity } \\
\left(\times 10^{-3} \mathrm{~Pa} \cdot \mathrm{s}\right)\end{array}$ & Gel time & $\begin{array}{l}\text { Uniaxial compressive } \\
\text { strength }\left(\times 10^{5} \mathrm{~Pa}\right)\end{array}$ \\
\hline \multirow{2}{*}{$\begin{array}{l}\text { Water glass } \\
\text { category }\end{array}$} & Alkaline water glass slurry & $1-100$ & Instantaneous-hours & $2-40$ \\
\hline & Non-alkaline water glass slurry & $1-100$ & Instantaneous-hours & $2-40$ \\
\hline \multirow[t]{2}{*}{ Acrylamides } & Acrylamide slurry & 1.2 & Instantaneous-hours & $3-8$ \\
\hline & Cement-Acrylamide & 1.2 & Instantaneous-hours & $3-8$ \\
\hline \multirow{2}{*}{$\begin{array}{l}\text { Urea-formaldehyde } \\
\text { resins }\end{array}$} & Urea-formaldehyde resin & $1.3-6.0$ & Minutes - tens of minutes & $30-100$ \\
\hline & $\begin{array}{l}\text { Urea-formaldehyde resin } \\
\text { Modified urea-formaldehyde resin }\end{array}$ & $1.3-6.0$ & Minutes-tens of minutes & $30-100$ \\
\hline Lignin & $\begin{array}{c}\text { Chromium lignin, lignin sulfate, } \\
\text { wood ammonium }\end{array}$ & $2-5$ & Minutes-tens of minutes & $2-128$ \\
\hline \multirow[t]{2}{*}{ Epoxy } & Furfuryl acetone epoxy resin & $6-100$ & hours & $400-1000$ \\
\hline & Low viscosity epoxy resin & $6-100$ & hours & $400-1000$ \\
\hline \multirow[t]{2}{*}{ Acrylates } & Methacrylates & $<10$ & Minutes-hours & $750-850$ \\
\hline & Acrylates & $<10$ & Minutes-hours & $750-850$ \\
\hline \multirow[t]{2}{*}{ Polyurethane } & Polyurethane prepolymers & $12-161$ & Minutes-hours & $1-120$ \\
\hline & Isocyanates & $12-161$ & Minutes-hours & $1-120$ \\
\hline
\end{tabular}

and its bonded concrete at different quartz powder dosages, and quartz powder with different particle sizes were studied. The base fluid used in this experiment had particle sizes on the same order of the diameters of the particles in the epoxy resin and quartz powder: $16.71 \mu \mathrm{m}, 18.49 \mu \mathrm{m}, 21 \mu \mathrm{m}, 26.26 \mu \mathrm{m}$, and $34.24 \mu \mathrm{m}$, respectively. The ratios of the epoxy resin to quartz powder were $1: 0,1: 0.2,1: 0.3,1: 0.4,1: 0.5,1: 0.6,1: 0.8,1: 1$ and the test temperature was set at $13-14{ }^{\circ} \mathrm{C}$.

The determination of the bonding shear strength is shown in Fig. 7. The test load used force control and a loading speed of $0.2 \mathrm{kN} \cdot \mathrm{s}^{-1}$; the tensile strength of the bond was measured using two C50 concrete blocks of $100 \mathrm{~mm} \times 100 \mathrm{~mm} \times 100 \mathrm{~mm}$. The test load was controlled by the displacement, and the loading speed was $2 \mathrm{~mm} \cdot \mathrm{min}^{-1}$ (Fig. 8).

Further, to study the applicability of the epoxy grouting material in prefabricated structures, in the case of mortise and groove joints, we designed a mortise and groove joint for a fullscale test. The full-scale test load diagram is shown in Fig. 9. The test of the tongue and groove joints was simplified; the test specimen consists of two rectangular parallelepiped reinforced concrete blocks with mortise and groove, and the middle mortise reserved $5 \mathrm{~mm}$ of perfusion epoxy grouting material. In the test, axial force was applied to one end of the specimen by the jack to simulate the casing load. The bending moment at the mortise was exerted by two equally spaced forces equidistant from the mortise. Force loading was used for the test loading.

\subsection{Test results and analyses}

Different quartz powder contents of the epoxy grouting material under the condition of their compressive strengths are shown

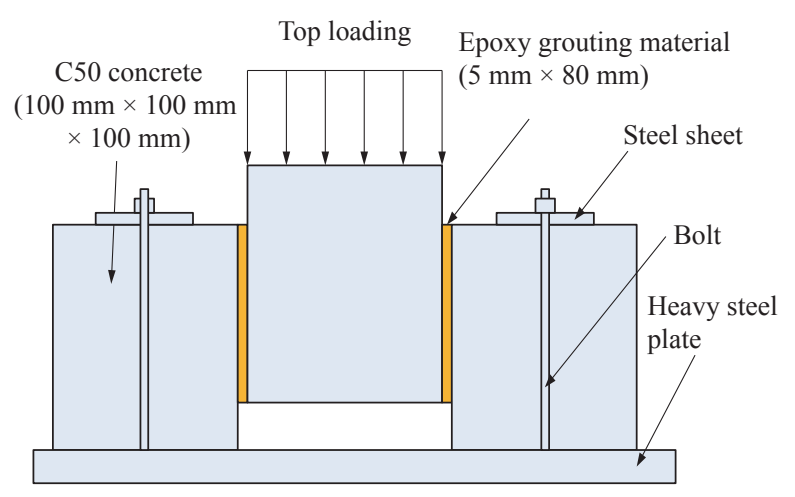

(a) Design diagram

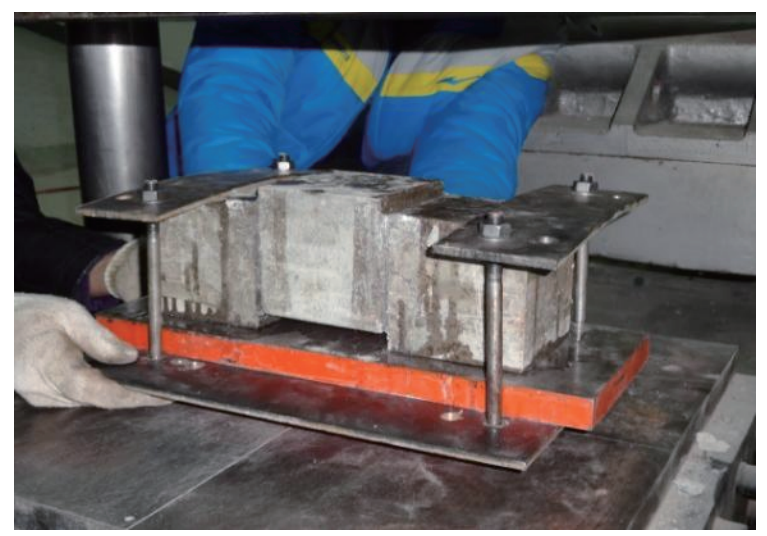

(b) Physical map

Fig. 7. Bonding shear strength specimen.

in Fig. 10. As shown, the compressive strength of epoxy mortar can exceed the compressive strength of C50 concrete (50 MPa). The compressive strength increases slowly when the ratio of epoxy resin content to quartz powder content is $1: 0.6$ to $1: 0.8$. 


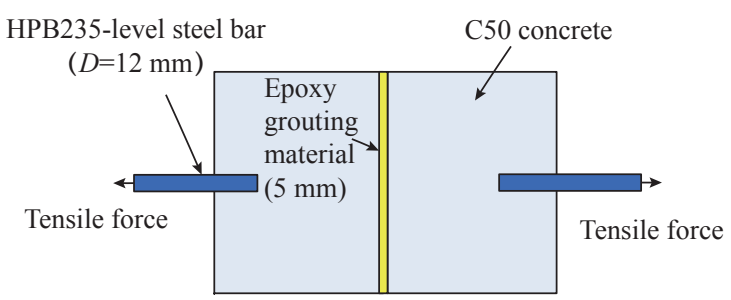

(a) Design diagram

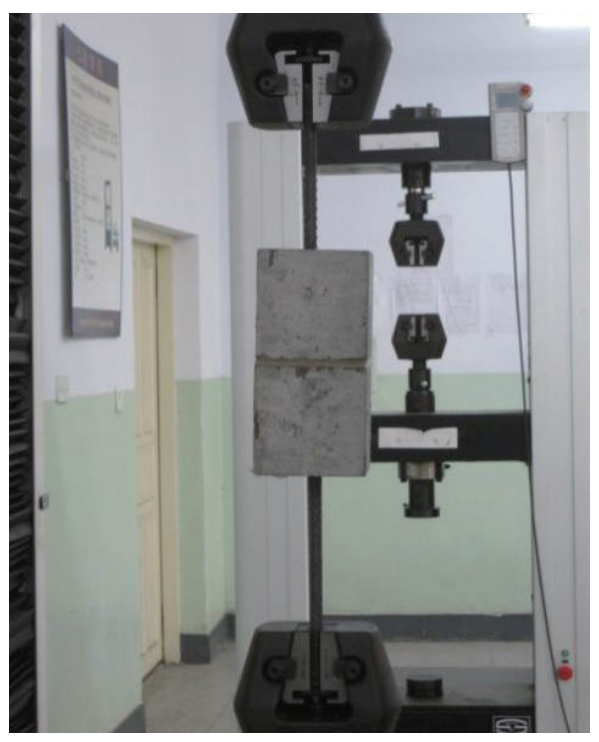

(b) Physical map

Fig. 8. Bonding tensile strength specimen.

At this point, the compressive strength is close to its maximum value. For different quartz powder content, the epoxy grout elastic modulus test results are shown in Fig. 11.
Fig. 11 shows that the elastic modulus of epoxy mortar increases gradually with the addition of quartz powder, and subsequently decreases gradually and approaches the maximum value when the ratio of epoxy resin content to quartz powder content is $1: 0.5-1: 0.7$. Quartz powder can increase the elastic modulus of epoxy resin because the modulus of the elasticity of quartz powder is much larger than that of the epoxy resin in a certain range of filler. Quartz powder and epoxy resin interface to better resist the crack beyond this range, and the role of quartz powder becomes less [6]. When the content of quartz powder is different, the shear strength of the epoxy grouting cement is shown in Fig. 12.

As shown in Fig. 12, when the ratio of epoxy resin content to quartz powder content is less than $1: 0.5$, the shear strength increases with the increase in the quartz powder content. When the ratio of the epoxy resin content to quartz powder content is $1: 0.5$, the shear strength reaches a maximum of $18 \mathrm{MPa}$, with an increase of $60.7 \%$ over pure epoxy (11.2 MPa); when the ratio of epoxy resin content to quartz powder content is greater than $1: 0.5$, the shear strength decreases. This is because when the filler content is small, the filler particles do not interfere with each other, and are evenly dispersed in the epoxy matrix. The filler is conducive to reducing the shrinkage of the adhesive system, thereby producing a uniform adhesive curing process of the residual stress [7]. Therefore, when the filler increases, the anti-shear mechanical properties will increase. However, when the amount of filler exceeds a certain proportion, the stress field generated by the filler overlaps with each other [8]. Therefore, the bonding performance of the adhesive decreases, and the shear resistance of the adhesive decreases. When the diameter of the quartz powder is different, the shear strength is as shown in Fig. 13.

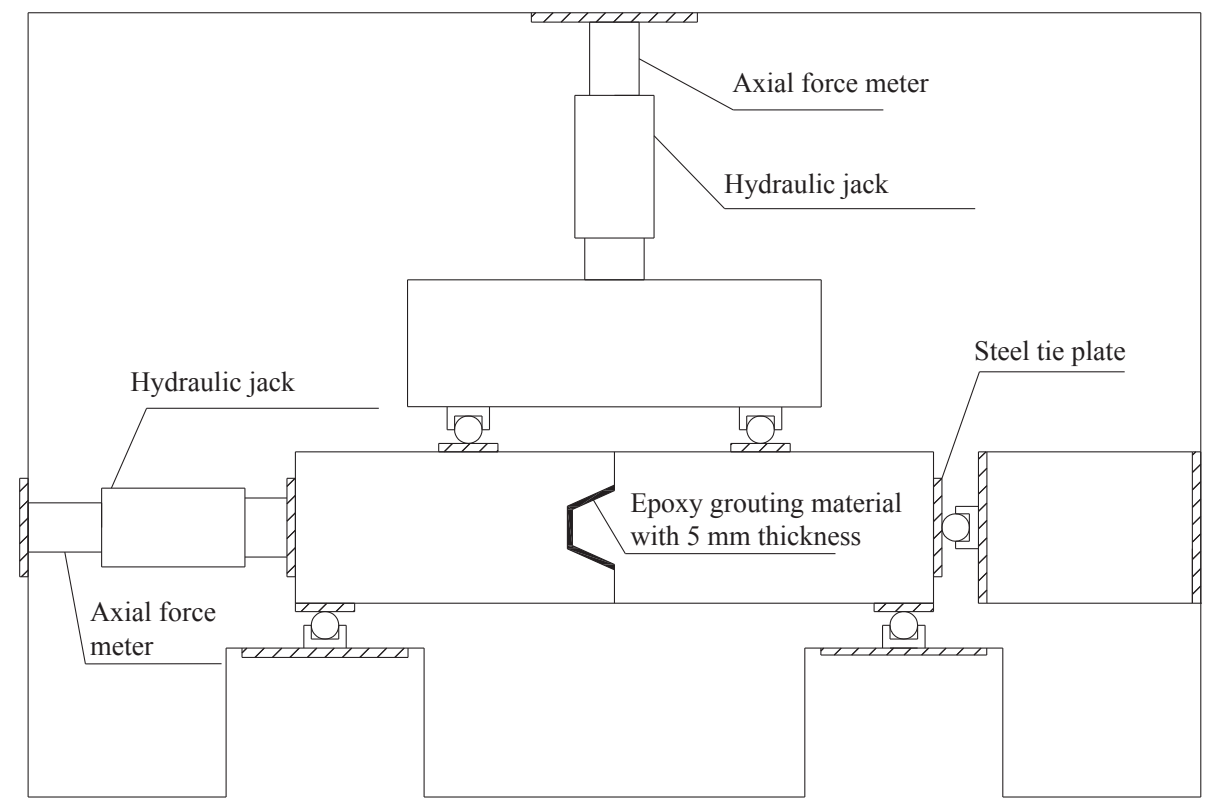

Fig. 9. Full-scale test loading diagram 


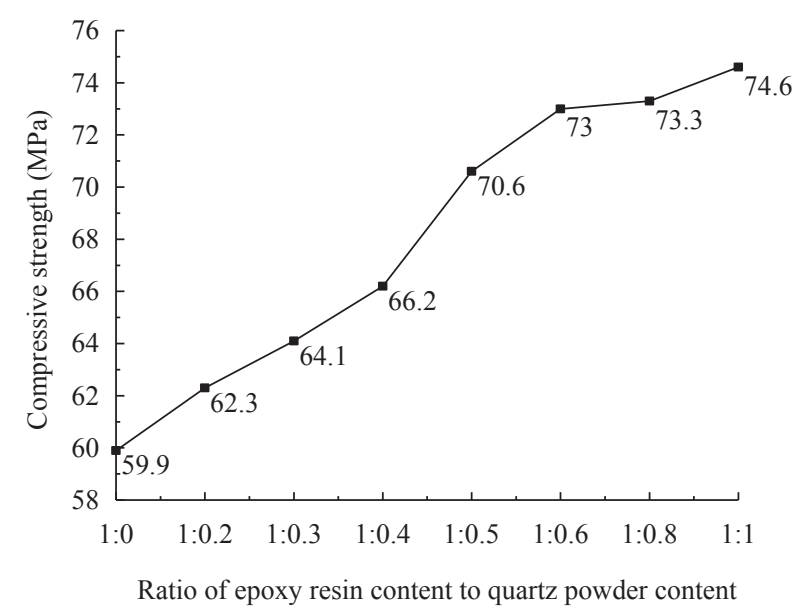

Fig. 10. Curve of the effect of quartz powder content on compressive strength.

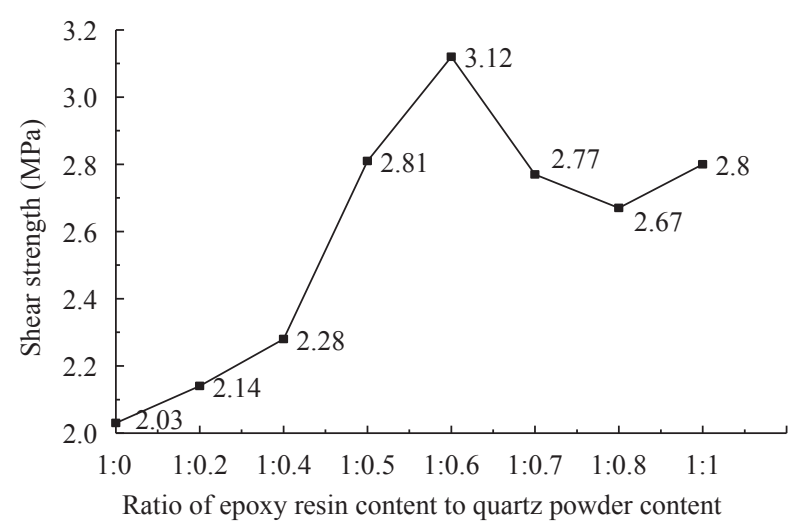

Fig. 11. Curve of the effect of quartz powder content on modulus of elasticity.

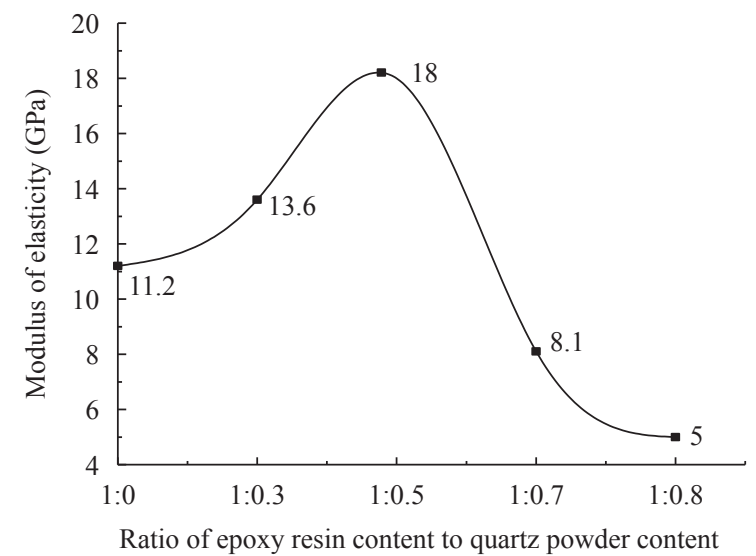

Fig. 12. Curve of the effect of quartz powder content on shear strength.

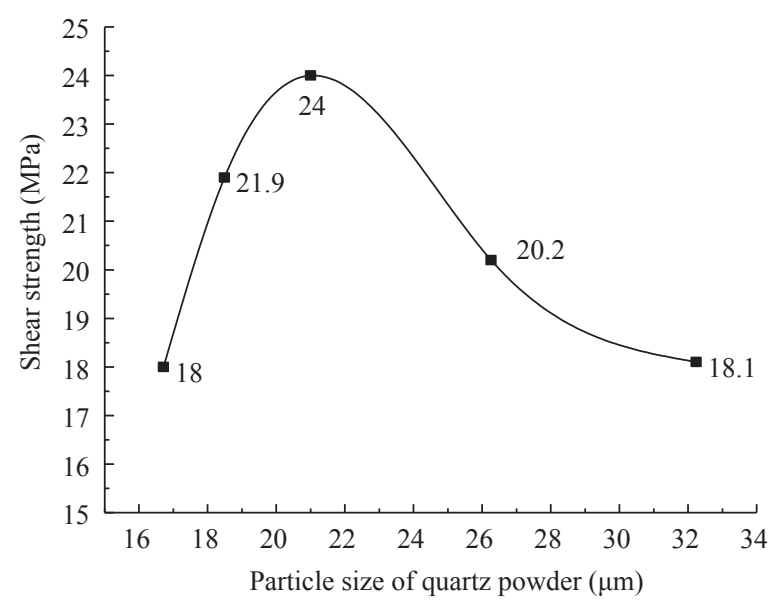

Fig. 13. Effect of particle size of quartz powder on shear strength.

Fig. 13 shows that as the particle size of the quartz powder (D50) increases, the shear strength of the epoxy grouting material-bonded concrete first gradually increases and subsequently gradually decreases. The quartz particle of size (D50) $21 \mu \mathrm{m}$ reached a maximum of $24 \mathrm{MPa}$. This is because when the particle size of the quartz powder (D50) does not exceed $21 \mu \mathrm{m}$, the total area of the quartz powder in contact with the concrete decreases with the increase in the particle size (D50) of silica powder after the epoxy grout is poured into the test piece. This allows more epoxy to penetrate the interior of the concrete, thereby increasing the shear strength and increasing the contact area between the epoxy itself; further, the concrete increases the shear strength. When the D50 exceeds $21 \mu \mathrm{m}$, the quartz powder precipitates during the curing of the epoxy grout, such that the contact area between the partial epoxy grout and the concrete loses its shear strength and the total shear strength decreases. We conclude that the particle size (D50) of quartz powder should be within the range of 18-25 $\mu \mathrm{m}$. A better formula can be obtained within the range of this size. When the content of quartz powder is different, the tensile strength is as shown in Table 2.

As shown in Table 2, the tensile strength of the adhesive surface of the epoxy mortar bonded with concrete specimens is far greater than the tensile strength of the concrete itself. The tensile strength depends on the tensile strength of concrete, whereas the quartz powder content and the size are of little relevance.

The form of the damaged full-scale test specimens is shown in Fig. 14. The full-scale test specimen damage is not along the mortise groove damage, but along the steel and concrete contact

Table 2. Tensile strengths.

$\mathrm{MPa}$

\begin{tabular}{lcccc}
\hline $\begin{array}{l}\text { Ratio of epoxy resin content to } \\
\text { quartz powder content }\end{array}$ & First group & Second group & Third group & Average value \\
\hline $1: 0$ & 2.53 & 2.88 & 2.96 & 2.79 \\
$1: 0.5$ & 2.52 & 2.79 & 2.84 & 2.72 \\
$1: 0.8$ & 2.66 & 2.73 & 2.81 & 2.73 \\
\hline
\end{tabular}


surface. The destroyed tenon concrete is stripped, and it is safe to use the epoxy grout for bonding the tongue-and-groove joints.

To obtain the flexural capacity of the specimen in a full-scale test under different axial forces, three test pieces were established for the damage basis: One is the open side of the joint that is $3 \mathrm{~mm}$, and the corresponding bending moment is $M_{1}$; the second is the end of the stage where the cracks are stable. At this time, the corresponding moment value is $M_{2}$. Next, the stress of the steel bars in the gutters is reduced simultaneously, and the corresponding moment value is $M_{3}$. By using a small value of bending moment as the axial bearing capacity of the bending strength, the results of flexural bearing capacity under different axial forces are as shown in Table 3.

\section{Premixed solidified soil backfill technology for open excavation of foundation pit}

To improve the waterproofing effect of the underground assembly-type structure, in addition to improving the waterproof performance of the fabricated type connector, a water stop curtain can be constructed on the periphery of the underground structure to prevent the groundwater from eroding the underground structure from the source.

The anti-seepage performance of the premixed solidified soil is better than that of the in situ soil. In the foundation pit construction, a composite structure composed of a bored pile and a premixed fluidized-solidified wall can be used to improve the waterproof effect of the underground prefabricated building.

Further, the foundation pit fat tank backfilling project in some underground works has the characteristics of a small working face. If the traditional in situ soil backfill method is used, largescale mechanical work cannot be performed and the backfill soil cannot be compacted. The use of premixed solidified soil for the backfilling of such works is a good method. Premixed solidified
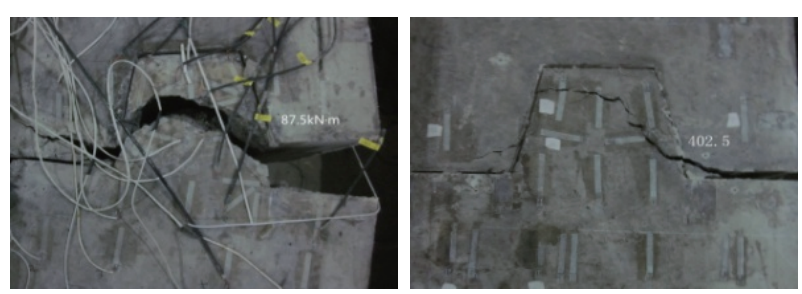

Fig. 14. Full-scale test failure morphology. soil has good compactness, high strength, strong fluidity, good impermeability, and low compressibility, and help to improve the nonuniform backfill of the base trench.

The premixed fluidized soil is composed of soil, cement, fly ash, sand, and the proper amount of water. The slump after mixing is $80-200 \mathrm{~mm}$, the strength reaches $0.5-10 \mathrm{MPa}$, and the cement can be replaced by the curing agent. When mixing, an admixture is added according to the soil quality and design requirements. Sand can be added without sand and pre-curing soil preparation. The mixing system is shown in Fig. 15.

The precuring soil pouring equipment, including the mixing equipment and pouring equipment, shall meet the following requirements: (1) the mixing, pouring equipment, production capacity, and equipment performance should meet the continuous operation requirements; (2) the mixing equipment should have a curing agent, water, soil ingredients, and metering functions; (3) the measurement deviation of the mixing equipment should meet the requirements of Table 4 .

Before pouring, the curing agent, admixture, and water shall be stirred first to form a curing agent slurry. The mixture shall use a special mechanical stirring, the mixing time shall be not less than $2 \mathrm{~min}$, the stirring shall be uniform, and the fluidity workability shall meet the requirements. The curing soil can be transported by a tanker, using pumping or chute pouring, the curing soil mixing to pouring completion time should not exceed $3 \mathrm{~h}$, the curing soil should be layered and block mode pouring is used, the pouring operations should be symmetrical, the pouring height difference should not be greater than $1 \mathrm{~m}$, the first pouring should not exceed $0.5 \mathrm{~m}$, and the upper pouring operation should be performed after the final condensation.

In case of heavy rain or continuous rainy weather, the unhardened surface of the fill body should be covered. After the completion of pouring, the surface should be covered and maintenance shall be performed immediately to prevent the loss of moisture. During the period, it is forbidden for pedestrians to pass through. After pouring the top of the building, the surface of the building shall be immediately covered with a plastic film or a geotextile to maintain the moisture. The curing time shall be no less than 7 days. The premixed curing soil shall be in the flow state, and the backfilling shall not require vibrating. Fig. 16 shows the premixed curing soil backfill construction picture. The premixed solidified soil has better impermeability than the

Table 3. Flexural bearing capacity under different axial forces.

\begin{tabular}{|c|c|c|c|c|}
\hline Axial force conditions $(\mathrm{kN})$ & $M_{1}(\mathrm{MPa})$ & $M_{2}(\mathrm{MPa})$ & $M_{3}(\mathrm{MPa})$ & Carrying capacity $(\mathrm{kN})$ \\
\hline 0 & - & 87.5 & - & 87.5 \\
\hline 500 & 230 & 250 & - & 230 \\
\hline 1000 & 335 & 326 & 330 & 326 \\
\hline 1600 & 471 & 470 & 480 & 470 \\
\hline 2000 & 593 & 500 & 550 & 500 \\
\hline
\end{tabular}




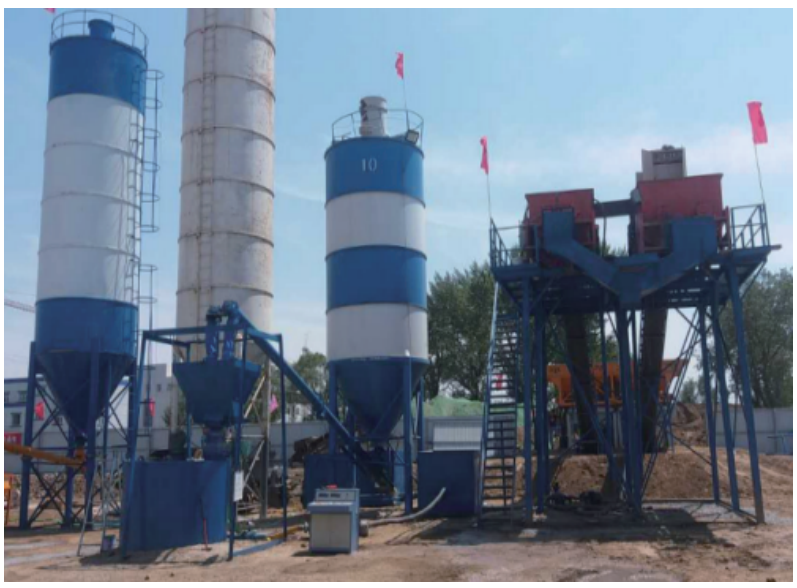

Fig. 15. Preparation and mixing system for premixed solidified soil.

Table 4. Measurement deviation of mixing equipment.

\begin{tabular}{lc}
\hline Raw materials & Measurement deviation \\
\hline Curing agent, water & \pm 2 \\
Soil & \pm 3 \\
Admixture & \pm 1 \\
\hline
\end{tabular}

original soil, and it can be used as a water blocking zone. The waterproofing of the underground structure is highly favorable. Fig. 17 shows the effect of backfilling with the premixed solidified soil for $12 \mathrm{~h}$.

\section{Conclusions}

(1) Considering the effect of the content of quartz powder on the compressive strength and elastic modulus of the epoxy grouting material, the optimum content of quartz powder is $1: 0.5-1: 0.8$. In this interval, with the increase in the content of quartz powder, compressive strength increase is small (close to its maximum), and the range of elastic modulus values is close to the maximum as well.

(2) Considering the effect of quartz powder content on the shear strength and the project cost of low-temperature epoxy grouting material-bonded concrete, and ensuring that the gratetype joint can fully exert its effect, the optimum amount of quartz powder is determined as $1: 0.3-1: 0.7$.

(3) Considering the effect of the size of quartz powder on the shear strength of low-temperature epoxy grouting materials, the particle size (D50) of quartz powder should be within the range of 18-25 $\mu \mathrm{m}$. This size range can yield a better formula.

(4) The tensile strength of concrete bonded with epoxy grouting material depends on the tensile strength of the concrete, and has little relation with the content and particle size of the quartz powder in the epoxy grouting material.

(5) Full-scale tests have shown that the use of epoxy grouting

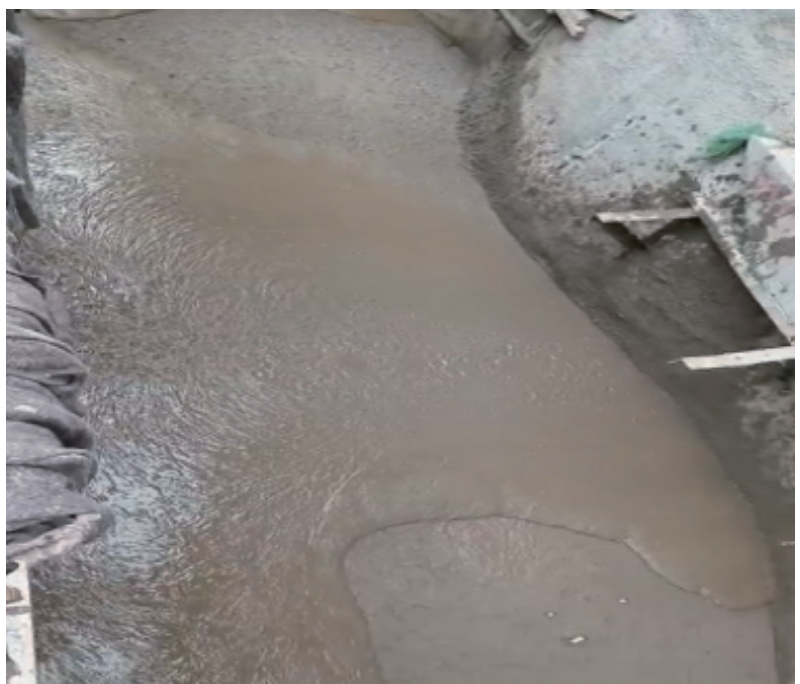

Fig. 16. Premixed solidified soil backfill.

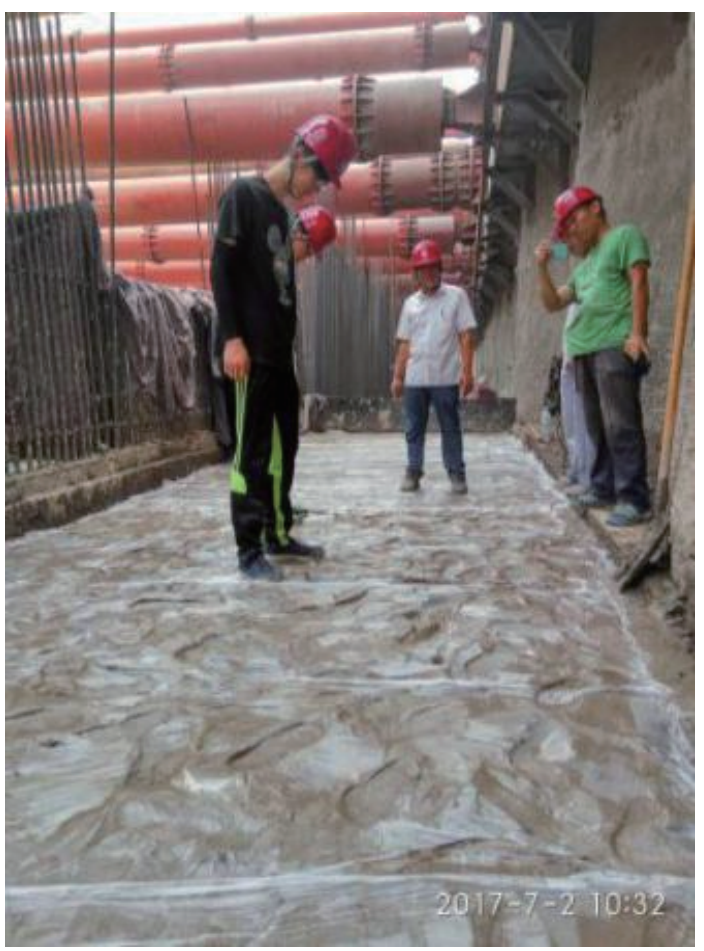

Fig. 17. Design sketch of premixed solidified soil backfill.

material to bond the grooved joints ensures that the mechanical properties of the joints are guaranteed and can meet the engineering needs. This waterproofing of underground construction is highly favorable.

(6) The use of premixed solidified soil for the backfilling of foundation pits in underground works is beneficial in improving the nonuniformity of backfilling foundation tanks. Additionally, the anti-seepage performance of premixed solidified soils is better than that of in situ soils. 


\section{References}

[1] Zhou J M. Design form and applicability analysis for deformation seam and joint of municipal tunnel [J]. Special Structures, 2016, 33(2): 60-65. Chinese.

[2] Ye J. Performance analysis of joints in prefabricated concrete structures [J]. Technology Wind, 2015 (15): 155. Chinese.

[3] Wang M N, Li Z Y, Wei L H. Prefabrication of tunnels and subway [M]. Chengdu: Southwest Jiaotong University Press, 2009. Chinese.

[4] Zhang C, Xu J. Construction technology for joint treatment of prefabricated building [J]. Bulding Constrction, 2017, 39(6): 807-809. Chinese.

[5] Fan H, Wang L. Waterproof technology of precast concrete buildings [J]. Housing Science, 2016 (3): 20-23. Chinese.

[6] You M, Cao P, Wei X H, et al. Effect of $\mathrm{SiO} 2$ filler on the elastic modulus and Poisson's ratio of epoxy layer [J]. China Adhesives, 2006, 15(3): 12-14. Chinese.

[7] Yuan J Y, Pan C Y. The essence and removing methods of internal stress due to volume shrinkage during kesin curing period $[\mathrm{J}]$. Chemistry and Adhesion, 1998(4): 234-240. Chinese.

[8] Li X D, Chen M C, Huang Y H. Plastic toughened by rigid filler [J]. Guangzhou Chemistry, 1996(3): 7-14. Chinese. 